\title{
Digital Public Services in Smart Cities - an Empirical Analysis of Lead User Preferences
}

\author{
Bernd W. Wirtz ${ }^{1}$ (D) Wilhelm M. Müller $^{1} \cdot$ Florian W. Schmidt $^{1}$ \\ Accepted: 6 October 2020 /Published online: 22 October 2020 \\ (C) The Author(s) 2020
}

\begin{abstract}
Smart cities (SC) attract constant criticism due their technocratic conceptualization. To solve this issue, scholars call for a citizen-centric approach aligning the $\mathrm{SC}$ agenda to the citizens' needs and preferences. However, examining SC user preferences is still in its infancy and only few studies provide empirical insights. By surveying 105 lead users, this article is able to predict the preferred type of SC services, the preferred channels for accessing smart services and the factors fostering SC service usage. In doing so, the study states a preliminary assessment of SC user preferences setting the scientific groundwork for citizen-centric SC concepts.
\end{abstract}

Keywords Smart city C Citizen preferences · Explorative study · Digital public services . Public administration

\section{Introduction}

In recent years, municipalities changed their policies and programs in favor of administering their city in a smart manner (Cardullo and Kitchin 2019; Woetzel et al. 2018). Such 'smart city' (SC) approaches use information and communication technology (ICT) via a city-wide network of interconnected sensors to augment the services provided by the municipality with regard to their accuracy, efficiency and effectiveness. The primary aim of this upgrade of urban public services is to improve the quality of life of the urban population (Pereira et al. 2018).

\footnotetext{
Bernd W. Wirtz

1s-wirtz@uni-speyer.de

Wilhelm M. Müller

wmueller@uni-speyer.de

Florian W. Schmidt

schmidt@uni-speyer.de
}

1 Chair for Information and Communication Management, German University of Administrative Sciences Speyer, Freiherr-vom-Stein-Str. 2, 67346 Speyer, Germany 
However, the objective of improving quality of life of citizens is viewed critically in the literature as this target is often set by SC project management without allowing the urban general public to participate in decision-making processes (Kitchin 2015; Hollands 2008). To shed light upon this issue, Vanolo (2016) investigates how the citizen is positioned as a figure in SC concepts. Furthermore, Johnson et al. (2020) outline patterns for citizen micro-transactions to get a clearer picture of how 'smart' citizens interact with their city. Hence, as SC approaches are converging toward citizencentricity, it is of crucial importance to get insight in how the citizen perceives the city, what SC services are of key importance from the citizens' point of view and which are the preferred transaction channels. Thus, in order to successfully plan and implement a $\mathrm{SC}$, "[t] he needs of all demographies and neighborhoods should be on the agenda when cities choose which programs to pursue" (Woetzel et al. 2018, p. 16). Unfortunately, "knowledge necessary to understand the process of building effective and smart cities in the real world has not yet been produced" (Mora et al. 2017, p. 20). In order to remain in line with a citizen-centric and holistic approach of planning and conceptualizing SCs, it is necessary to involve people with prior and profound digital experience and technological affinity. According to Von Hippel (1986, p. 796), these 'lead users' "have real-life experience with novel product or process concepts $[\ldots]$ and so are in a position to provide accurate data on needs related to such future conditions". As the practical implementation of SCs is still in its infancy, most citizens cannot estimate or express their preferences concerning their SC usage behavior. By adopting a lead-user approach, the study at hand is able to investigate prospective citizen needs "years before the bulk [of SC users] encounters them" (Von Hippel 1986, p. 796).

Against this background, this study aims to determine the spectrum of public services that, from the lead users' point of view, form the nucleus of a SC initiative. Furthermore, the study seeks to identify the type and design of the channels through which lead users intend to interact with their SC. Based on this objective, two fundamental research questions arise for the study at hand: Which of the SC services are particularly important to the inhabitants? Which channels are of major interest for the interaction of citizens with public smart services and smart devices?

In order to shed light on these questions and to find empirical answers to them, this paper proceeds as follows: Section two recalls the findings of SC literature with regard to frameworks and its connector points to the citizens in order to state the theoretical foundation of the ensuing empirical survey. Building upon the insights from SC research, section three provides the reader with a derivation of a conceptual sketch of connecting citizens to the various public smart services providing the preliminary work for empirical investigation. Hence, section four presents the methodology of the leaduser-survey, reports its findings and addresses the research questions mentioned above. Section five discusses these findings and derives conclusions for further research and for practical implementation of SC projects.

\section{State of Research}

Up to now, the development of SC approaches primarily focussed the technological upgrading of a city's infrastructure by interconnected sensors, electronic devices and municipal databases while citizen-centered design of SC systems just recently pressed 
into the fore (Cardullo and Kitchin 2019). A growing number of SC scholars claim that urban digitization can be called 'smart' if and only if the citizen is put to the center of the system and is given the ability to participate and co-create in providing those public services associated with the SC venture (Abella et al. 2019). In the course of the technical development of the Internet and ICT devices, the technological expansion of urban infrastructure has increasingly become the predominant issue of SC research (Chourabi et al. 2012). Despite scientific progress in conception and design of a systemic approach for a SC, the unattended component of citizen orientation and needs-based development of public smart services has attracted constant criticism (cf. Joss et al. 2017; Hollands 2015; Kitchin 2015; Allwinkle and Cruickshank 2011; Hollands 2008).

Consequently, focussing 'citizen-centricity' led to a cleavage in SC research dividing the literature into two main perspectives on the SC: the technology-oriented approach and the people-oriented approach (Marrone and Hammerle 2018; Mora et al. 2017; Angelidou 2015). With regard to the importance of the people-oriented approach, Angelidou (2015) argues that besides the technological push in augmenting the capability for open data access and digital networking, applications pull SCs towards successful implementation. Apart from advancing and activating their human and social capital, SCs also need to alter their citizens' attitude with regard to a "sense of agency and meaning" and to use "[t] echnology responsive to needs, skills and interests of users, respecting their diversity and individuality" (Angelidou 2015, p. 103).

Biagi et al. (2018) assess the perceptions of urban citizens by random interviews in public places to determine the main components of urban quality of life. The results show that the perceived quality of life associates with the prospective range of choices following the accessibility of public services, the individual allocation of time, and social interactivity. To get deeper insight into the determinants of citizen satisfaction and the perceived quality of life as key target of SC initiatives, Macke et al. (2019) interrogate 392 citizens with regard to their material well-being, their usage of public urban services and of the perceived sense of community confirming the abovementioned assumption. Empirical insight into the citizens' expectations and benefits of digitized public services as well as into the preferred channels of $\mathrm{C} 2 \mathrm{G}$ interactions is given by Lamberti et al. (2014). With regard to the expected benefits, the study finds that cost, time and savings in $\mathrm{C} 2 \mathrm{G}$ interaction are the most important motivation for citizens whereas unconstrained access to public service usage, immediate feedback concerning queries as well as multichannel interaction and interoperability also provide important benefits. Since it remains unclear how citizen engagement may improve public smart services in SCs, Allen et al. (2020) show that the frequency of feedback provided by the users induced a higher clearance rate of public service inquiries in subdistrinct service units in general. Finally, in order to clarify the value created by ICT-based public services, El-Haddadeh et al. (2019) surveyed 313 citizens in the United Kingdom. Based on the technology acceptance model (TAM), the authors discover that the perceived value of these public smart services and the willingness of the citizens to use the services and actively engage in providing personal data primarily depends on whether the citizen perceive the service as being useful in daily life.

Surprisingly, current research especially lacks in empirical studies assessing the preferences of SC citizens. While there exists a profound body of conceptual literature 
deriving participation approaches from Open Innovation and e-Government, there exist only few studies providing significant empirical insight to the citizens' preferences regarding the types of public services or their mode of provision. As SCs in general are still at an early stage of exploration and implementation, the experiences of SC lead users are required to analyze the behavior of smart citizens. Drawing conclusions from lead-user behaviour on the prospective behaviour of the broad mass of society is a viable proposition, because these lead users entail citizens that adopt smart service solutions prior to the mainstream and thus can be assumed to state the user profile of the future generation of 'smart citizens'. In particular, lead users already have access to and use smart services comparable to those of a SC (e.g. location-based apps, social media, etc.) such that they act as early adopters and trendsetters for SC service usage. Refering to the remarks of Von Hippel (1986), investigating the lead users' preferences concerning the range of public smart services offered and their behavioral intention to use certain service provision channels provides valuable insights for designing and implementing the SC services.

\section{Smart City Service Framework}

To conceptualize a SC in a citizen-centric manner, Anttiroiko et al. (2014) reinterpret SCs as platforms for public smart services and identify three major types of public eservices, i.e. information services, interactive services and transaction services. According to Heaton and Parlikad (2019), public service provision in SCs needs to overcome siloed interaction with the citizens by integrating the multitude of public SC services into a single standardized service platform. Determining what citizens prefer and how they should be involved in a SC initiative is nowadays one of the major concerns of people-oriented SC research (Johnson et al. 2020; Abella et al. 2019; Cardullo and Kitchin 2019; Joss et al. 2017). While large parts of the literature investigated the role of the citizens and participatory elements in SC initiatives (cf. Cardullo and Kitchin 2019; Webster and Leleux 2018; Joss et al. 2017; Vanolo 2016), studies investigating preferences and needs of citizens as customers of smart services are rather scarce.

\section{Smart City Technology}

Against this background, this study follows the notion of Dreyer et al. (2019, p. 57) defining 'smart services' as "individual, highly dynamic and quality-based service solutions that are convenient for the customer, realized with field intelligence and analyses of technology, environment and social context data $[\ldots]$, resulting in cocreating value between the customer and the provider in all phases from the strategic development to the improvement of a smart service". Consequently, offering public smart services to the citizens requires the application of Internet-of-Things-(IoT)technology for the sake of perceiving and transmitting these data via the internet. According to Wirtz et al. (2019b), the technological foundation of IoT-based service provision is set upon three essential components of ICT technology: data centers, M2M network/internet infrastructure and endpoint devices. While data centers perceive and store data according to the systemic demand for data, the SCs' M2M networks ensure 
secure transmission and distribution of required data from the central urban databases to the peripheral endpoint devices in the field, and vice versa (Vanolo 2016). In the end, data arrives at and departs from service endpoint devices which serve as a service interface and connector point between the smart service provider (i.e. municipality and suppliers) and its customers (Heaton and Parlikad 2019).

\section{Smart City Administrative Units}

Despite the above-mentioned commonalities in the mode of functioning of hardware and software processes, smart services differ significantly in their design and their field of application. Focussing European cities, Gil-Garcia et al. (2015) identify government, society and the physical infrastructure as the major branches of SC services. In contrast, Neirotti et al. (2014) distinguish 'hard' and 'soft' service domains. While hard domains refer to "the city settings in which the vision of a city that senses and acts can be the most applicable $[\ldots, \ldots]$ soft domains include areas such as education, culture, policies that foster entrepreneurship, innovation and social inclusion, as well as communication between local public administration and the citizens" (Neirotti et al. 2014, p. 27). Against this background, Wirtz et al. (2019a) identify four major SC service segments smart governance \& e-government, smart social services, smart resources \& smart environment, smart mobility \& smart infrastructure. In order to state a concise outline of the various service domains for the ensuing interrogation of lead users, this study reinterpretes the SC service segments stated by Wirtz et al. (2019a) as 'administrative units' as the responsible suppliers for hosting, administering and providing the associated services differ across the segments.

\section{Smart City Service Portfolio}

Summarizing the various services reveals the city's range of available smart services. By outlining the type and constellation of services, this portfolio of SC services demonstrates the most significant SC service segments and indicates the pursued urban development strategy. In order to identify related or similar services, it is conceivable to typecast the services within a segment (cf. Wirtz et al. 2019a). For this purpose, the various service domains of the SC service portfolio assemble services being similar in their objectives, their target groups and/or their functionality (Gil-Garcia et al. 2015; Neirotti et al. 2014). In order to query the lead users' preferences with regard to the different types of SC services, the service portfolio splits the respective service segments up into three to four service domains (see Fig. 1). If, for instance, a citizen survey reveals a high preference for smart health services, the result indicates a development priority for the SC healthcare domain thus shifting the emphasis of SC policy to the segment of smart social services. Hence, the lead users' preferences concerning SC service segments and domains state a preliminary notion of the priorities of strategic SC development.

\section{Smart City Channels and Smart City User Interface}

Given the strategic composition of the SC's service portfolio, investigating user preferences for service provision channels that constitute the user interface between 

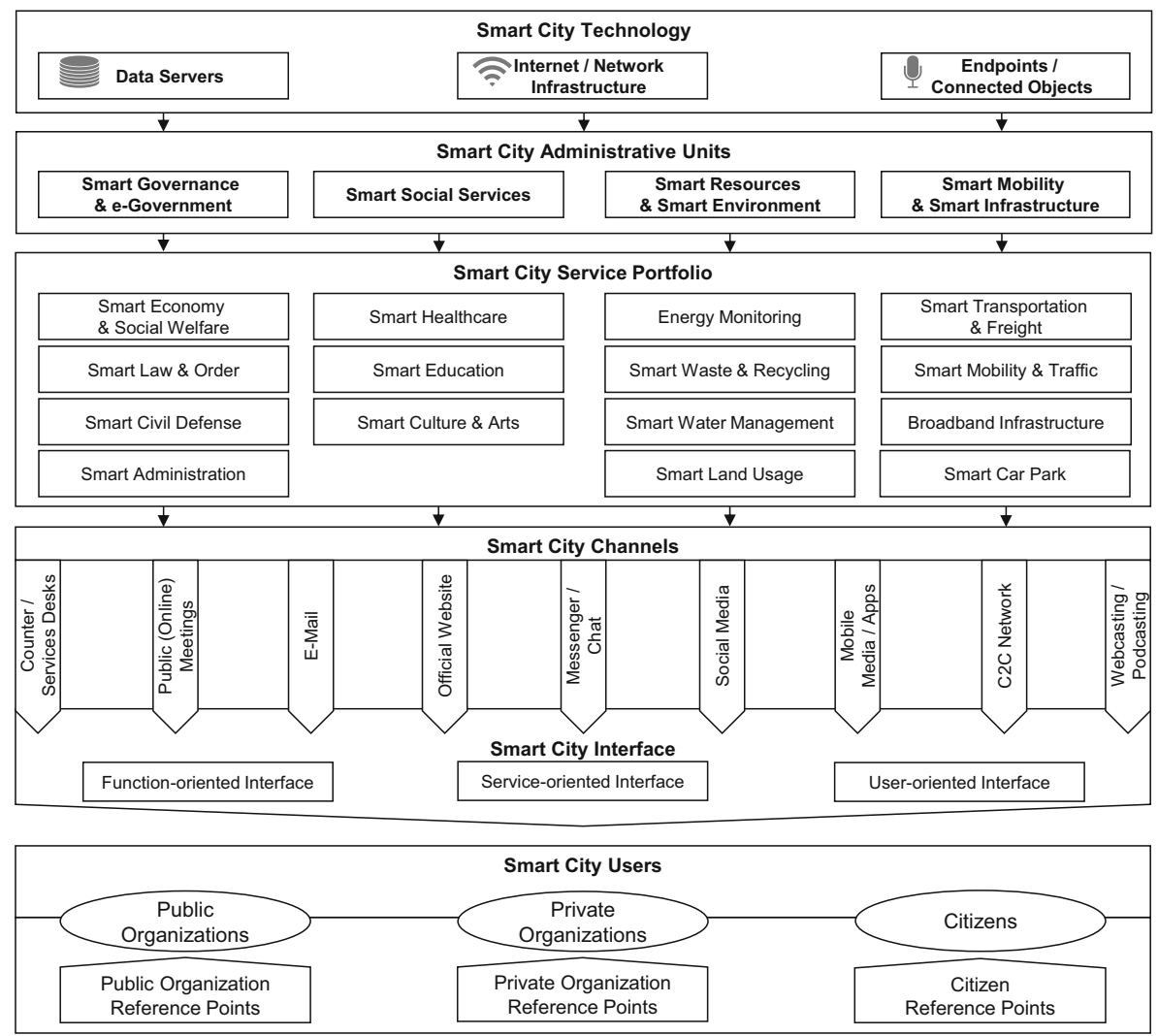

Fig. 1 SC Service Provision Framework, own elaboration

the citizen as SC users and the municipality with its service suppliers represents an important issue as the strengths and weaknesses of the various channels significantly shape the users' perception of SC appearance. Since successful implementation of SC policies requires service usage and citizen participation, it is crucial for SC planning and design to determine the users' most preferred channels ex-ante. By identifying conceivable channels for citizen interaction in e-government applications, the egovernment survey of the United Nations (2014) provides a conceptual basis for setting up such a multichannel frame for public service provision. Wirtz and Langer (2017) seize this structure to analyze the strengths and weaknesses of government services in terms of their communication and service provision capacities as well as their cost efficiency. For the case of SCs, online services gain center stage as most features of SC services rely upon ICT to ensure ubiquitous access to public services and continuous timeliness of available information. Aiming to investigate online interactivity of government authorities and citizens at the local level, Mossberger et al. (2013) study the usage of social media and interactive citizen contact points in the 75 largest U.S. cities. For the years 2009, 2010 and 2011, the authors discover a great increase in social media usage for connecting citizens and local governments indicating social media as a key channel for providing municipal online services. In addition, Anttiroiko et al. (2014) elaborate four major functions of public smart services, i.e. communication 
and short messaging, content sharing, social networking and crowdsourcing, confirming the suitability of social media for $\mathrm{C} 2 \mathrm{G}$ interactions. Due to these considerations, the composition of the channels for providing public services in SCs follows an integrated channel strategy (cf. Wirtz and Langer 2017) combining efficient offline channels with the emergent online solutions. Consequently, SC service channels comprise counters/service desks, public (online) meetings, e-mail correspondence, official websites, messengers/chats, social media, mobile media/mobile apps, C2C networks as well as web- and podcasting.

\section{Smart City Users}

Although the relevant literature often focuses the citizen as the main target group of SC measures (cf. Cardullo and Kitchin 2019; Heaton and Parlikad 2019; Vanolo 2016), Johnson et al. (2020) challenge this rather restrictive limitation to the citizenship of a SC user. Therefore, the authors "extend the term to include all those involved in generating transactions within the smart city" (Johnson et al. 2020, p. 2) adding noncitizen residents, visitors, guests and tourists to the group of SC stakeholders. Accounting for such a broad range of stakeholders using a bunch of SC services, the approach at hand refers to the term of SC users or 'smart users' whereas the citizens remain primary actors within the group of SC users. However, secondary SC users, who are not inhabitants of the city, often rely upon private and public intermediaries providing local services (Visnjic et al. 2016), e.g. public immigration authorities or private travel businesses. Thus, the group of SC users also entails those public and private organizations that act as continual user of the city's service temporarily forwarding the service features to visitors, guests and non-native residents.

Summarizing the hypothesized scope and configuration of public service provision in SCs, Fig. 1 illustrates the organizational structure of the administrative units of SCs, their associated services agglomerated in the SC service portfolio as well as the provision channels culminating in the SC service interface that links the features of the services to their customers.

To sum it up, Fig. 1 outlines the spheres of interest for the upcoming lead user survey. In order to derive a citizen-oriented roadmap for SC implementation, it is crucial to determine which of the administrative units receives the highest attention, which services are of major importance and which are the preferred channels for citizen interaction from the lead users'point of view. Hence, Fig. 1 states the research framework highlighting the core topics of the questionnaire, i.e. relevance of SC administrative units, intention of SC service usage as well as the preferences with regard to the choice of suitable provision channels for SC services.

\section{Methodology and Results of the Lead-User Survey}

\section{Methodology and Data Collection}

According to Von Hippel (1986), deriving conclusions concerning prospective user preferences and usage behavior by investigating lead-users requires a four-step approach including (1) the identification of new trends and product or service 
innovations, (2) the identification of lead users setting the trend by their experience and their needs, (3) the analysis of lead user demand and (4) project the lead users' preferences and usage behavior onto the intended market.

To identify appropriate lead users and to explore the relevance of and the need for the various public SC services, this study relies upon a survey of postgraduates (master, $\mathrm{PhD}$, etc.) from our university concerning their usage of smart services and their perception of various types of public online services. However, the postgraduates voluntarily took part in the survey and were not offered any incentives to stimulate their participation. To ensure a consistent interrogation of the participants with regard to their usage and assessment of digital services, the survey used a single, standardized questionnaire assessing the state of the respondents ' digital experience by the hours spent on the internet and by the frequency of smart service usage. After cleansing the data set of incomplete and inconsistent data, the final sample consisted of 105 participants most of which were between 25 and 34 years old (74\%) and were part of a public administration postgraduate programme at our university (79\%). Furthermore, the sample revealed a profound digital experience in being present on the internet and using smart service due to $81 \%$ of the participants being online more than 10 hours per week and $88 \%$ of the participants being familiar with using smart services in daily life. Furthermore, $44 \%$ of the participants claimed to be frequent users of smart services. Consequently, the selected sample represents a snapshot of the 'creative class' (Nam and Pardo 2011) of a city such that these participants may be considered as a sample of lead users for SC services. Following the argument of Von Hippel (1986) and Lüthje and Herstatt (2004), members of the creative class of a city already face the prospective benefits and struggles of smart service usage in tomorrow's SCs as they possess (a) the motivation to adapt to new forms of mutual interaction and communication, (b) the means to experience smart service usage by ICT and (c) the opportunity to learn their usage behavior and preferences.

\section{Lead Users' Preferences Regarding SC Services}

To investigate their preferences concerning the various types of SC services, the participants were asked to weigh the importance of the various branches of SC services by distributing up to 100 points among the respective service segments. Fig. 2 shows the average usage relevance of the respective branches of SC service provision. On average, the respondents awarded the branch of smart mobility \& smart infrastructure the highest relevance $(51.97 \%)$. Furthermore, the results showed a lower but still significant emphasis on smart governance \& e-government services (22.93\%). In contrast, the participants considered the branches of smart social services $(16.08 \%)$ and smart resources \& smart environment $(9.01 \%)$ as less important.

Turning toward the SC service portfolio to understand which type of SC services is most relevant from the lead users' point of view, the participants weighed the relevance of service usage for SCs by assigning weighting points to the respective service domains. Fig. 3 presents the participants' preferences concerning the various SC service domains.

For the most important branch of smart mobility and infrastructure, the respondents assigned the greatest emphasis to smart mobility \& traffic, i.e. those services that help citizens to overcome distances in a crowded city in a forward-looking way (46\%). 
$60 \%$

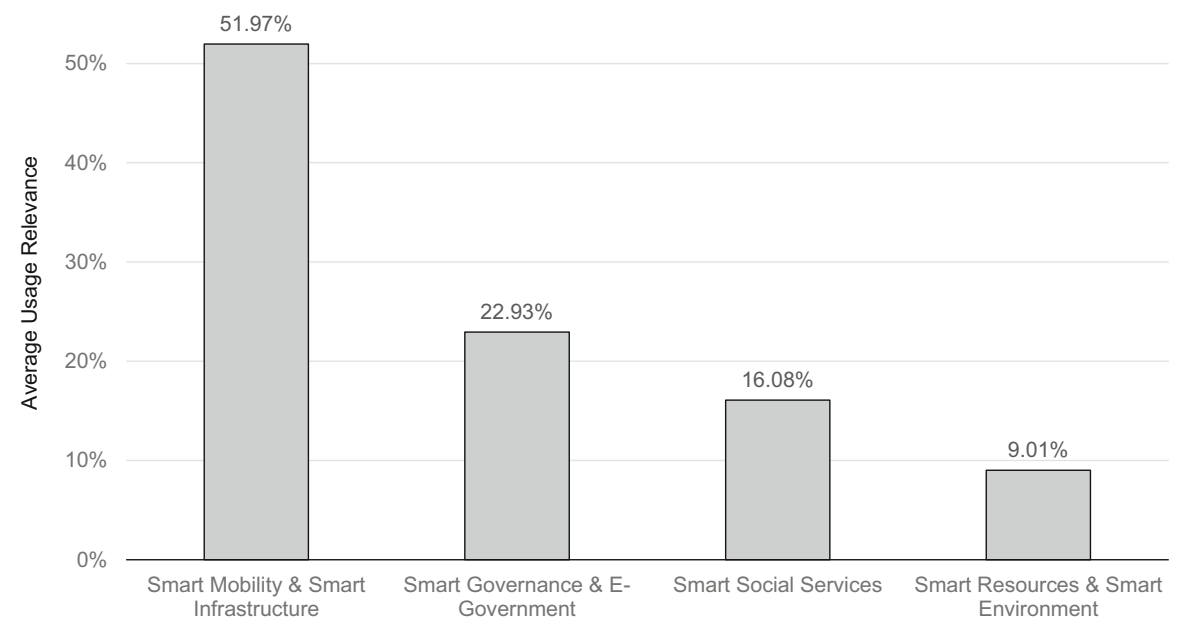

Fig. 2 Relevance Weights of SC Service Branches / Administrative Units

Furthermore, the participants also evaluated distributing goods and services across the city by smart transportation and freight as being an important operational task whereas the broadband and internet infrastructure $(11 \%)$ and parking cars $(8 \%)$ received lower attention.

For smart governance and e-government, the survey reveals a great relevance of augmenting municipal public administration by ICT-based smart service solutions (39\%) and providing 'smart solutions' for the economy and for those institutions tasked

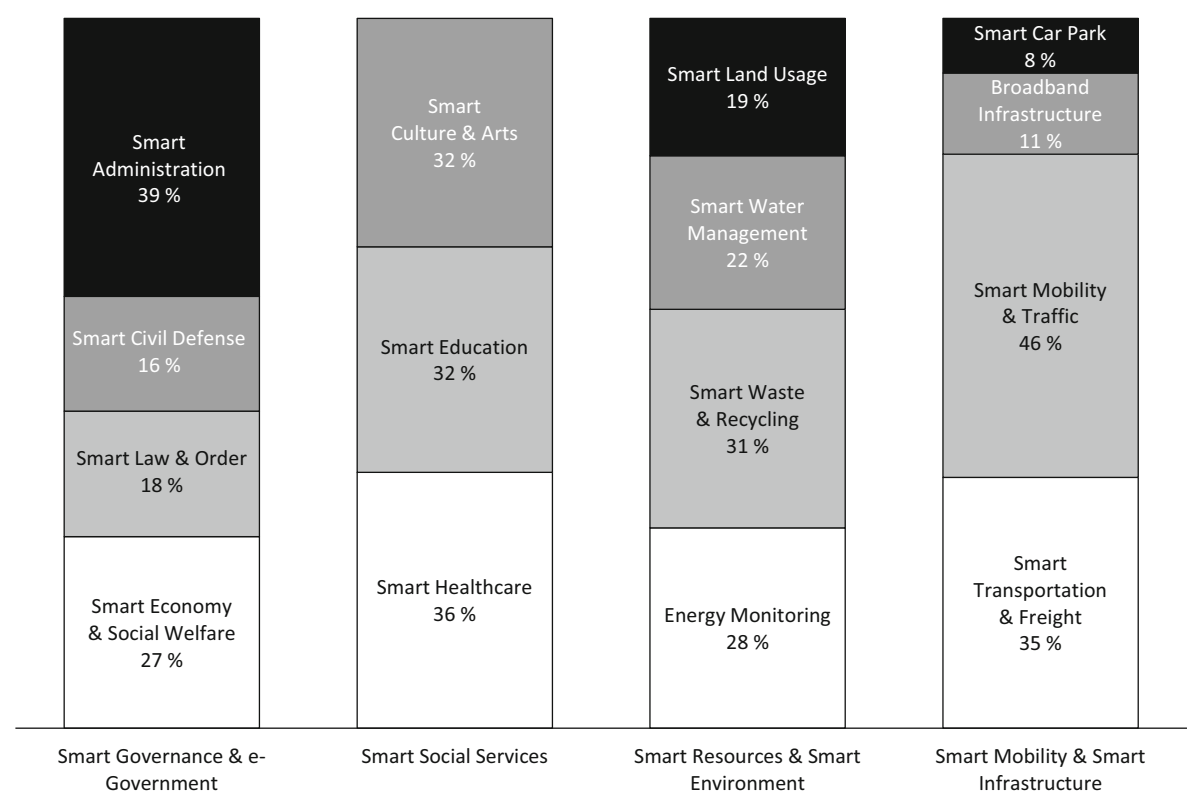

Fig. 3 Preference Weights of SC Service Domains within their Administrative Units 
with upholding social standards (27\%). However, the participants rate prospective smart services of judicial authorities as less important (18\%) and state a rather low interest in civil defense units offering smart services to the urban public (16\%).

Considering the domain of 'smart social services', the participants advocate for equal importance of the proposed service such that smart culture and arts (32\%), smart education $(32 \%)$ and smart healthcare $(36 \%)$ are viewed as equally important. With regard to the service associated with 'smart resources \& smart environment', the participants emphasize the importance of smart solutions to waste disposal and recycling $(31 \%)$ and to monitor energy consumption and distribution $(28 \%)$. However, with regard to their low emphasis, smart social services and smart environmental services as a whole seem to be of secondary interest.

In order to gain insight into the preferences concerning the provision channels of public SC services, the participants evaluated their preferred channels for accessing public data and municipal services. Fig. 4 presents the preferences with regard to SC service channels.

Given the opportunity to access smart services on the way using smart devices, such as smartphones or tablets, access to mobile services achieves the highest popularity among the participants (19.02\%). Furthermore, 'conventional' access to online services via offical websites and online portals (11.46\%) or via email-based accounts (10.92\%) are still of high relevance to the lead users. Emergent forms of online interactions and communication via social media $(10.68 \%)$ or via messenger/chat rooms $(8.22 \%)$ receive a moderate preference whereas the respondents mostly reject the traditional forms of service interactions of counters/service desks (3.18\%) and public meetings $(2.16 \%)$ showing a significantly lower relevance.

Besides the preferences for SC services and the associated provision channels, it is crucial to examine the characteristics of successful SC services. To obtain an appraisal of service quality from the users' point of view, the participants stated their perceptions of effective and user-friendly service provision in SC environments. To achieve this,

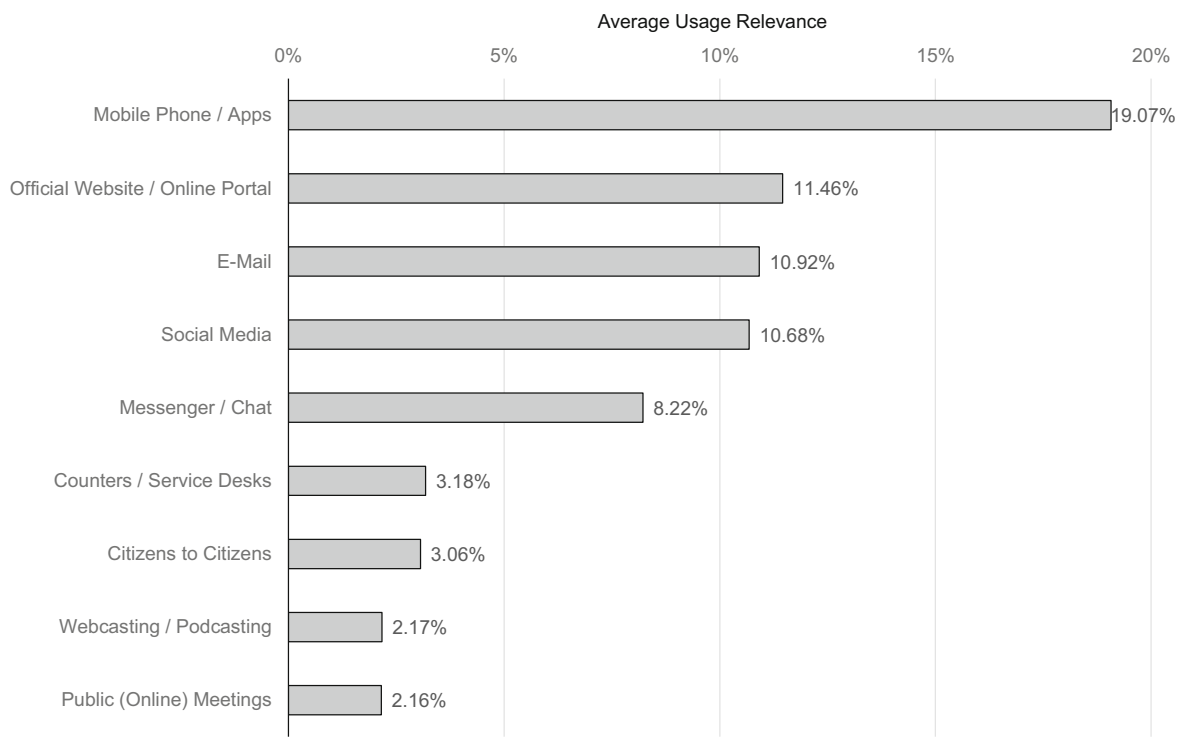

Fig. 4 Usage Preferences for SC Service Channels 
the participants were asked to identify those factors that characterize successful SC services. To account for varying perceptions of service quality, the questionnaire distinguished three dimensions of SC service success, i.e. function- and serviceoriented success (Fig. 5) and technological success (Fig. 6). It is worth mentioning that when asked whether function- or service-oriented success factors dominate the overall success of SC service, the majority of the participants assigned equal relevance to both dimensions.

With regard to function-oriented success factors, the participants confirm the suggestions of the literature that ease of use and user-orientation represent important aspects of successful smart services (12.23\%). In addition, information and service quality $(9.08 \%)$ as well as responsiveness to citizen requests $(7.99 \%)$ also state important function-oriented factors for SC service success. Surprisingly, success factors related to the implementation of mobile applications (4.93\%) and social media (3.32\%) as intermediaries of SC services play a minor role thwarting the results of the previous survey.

Considering service-oriented success factors, the participants advocate for an extensive set of full online services provided by a SC (11.40\%) ensuring both smart service breadth (i.e. a wide range of SC services) and smart service depth (i.e. a comprehensive set of service features) $(7.15 \%)$. According to the participants, providing citizens with the opportunity to track the processing status of their queries online thus making public administration procedures more transparent and traceable also states an important feature of SC service systems (6.83\%). In contrast to the literature, the lead user survey finds that participatory SC services $(2.97 \%)$ and open access to urban data $(2.52 \%)$ possess a rather low relevance.

Besides the function- and service-oriented success factors of SC services, the technological characteristics of the system state an essential prerequisite for smart service usage. As the success factors associated with IT technology state first-order

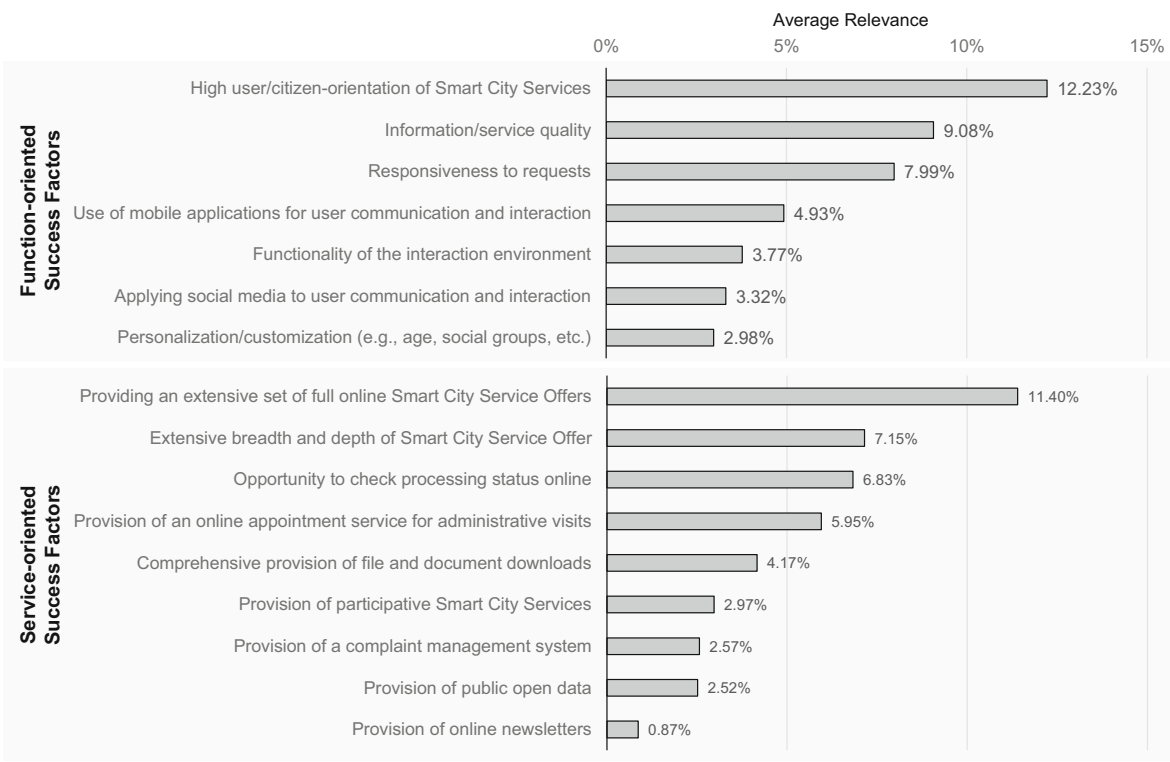

Fig. 5 Relevance of Function- and Service-oriented Success Factors 


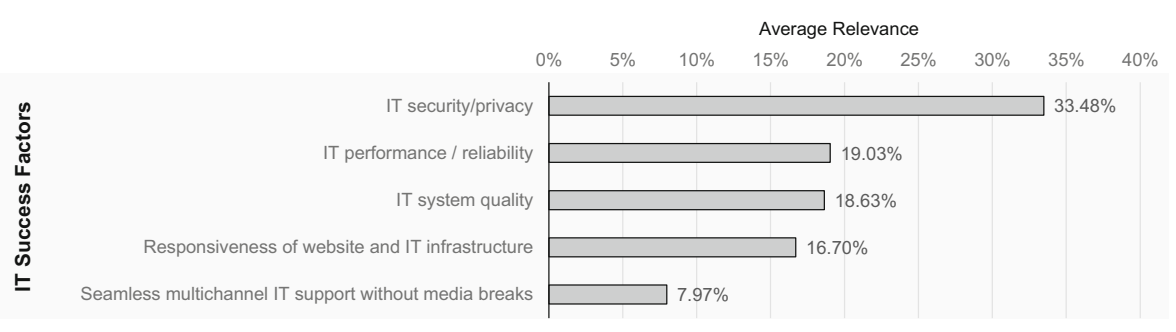

Fig. 6 Relevance of IT Success Factors

conditions for setting up a city-wide data system upon which a SC may be based (Wirtz et al. 2019a), the study assessed the respondents' estimates of relevant IT success factors separately to obtain the systemic characterizistics most relevant to SC implementation (see Fig. 6).

According to the respondents' appraisal, IT security and the maintenance of privacy appears as the most relevant factor for smart services (33.4\%). Furthermore, the participants also evaluated the system's reliability, robustness and performance as relevant factors for the success of urban smart services (19.03\%). Furthermore, IT system quality encompassing ubiquitous accessibility, interoperability of the system and compatibility with the citizens' devices states a moderately important aspect for SC system success $(18.63 \%)$ besides the responsiveness of the associated software and websites $(16.70 \%)$. In contrast, distributing the presence and accessibility of smart services across a multitude of channels seems to be of little relevance for the success of SC services (7.97\%). This indicates that the users are more interested in the establishment of reliable and secure online and mobile urban services than in a seamless distribution of services across all channels available by technical opportunities.

All in all, the results of the lead user survey firstly shows a clear user preference for smart mobility services and for smart public administration. Second, the respondents express their intention to favor digital channels, i.e. mobile applications, online platforms or websites over traditional analog channels such as public meetings or service desks. Thus, lead users expect the analog channels of accessing public services to dwindle in importance giving room to the establishment of digital alternatives. Third, the survey concludes that achieving ease of use and user-friendliness for smart urban services provided in SCs and providing a broad service spectrum with versatile service features while ensuring reliability, robustness and security of the underlying IT system states a recipe for a $\mathrm{SC}$ 's success.

\section{Discussion and Conclusion}

In order to draw conclusions about the preferences of SC users, the study at hand surveyed the attitudes and intended preferences of lead users toward prospective municipal public smart services. Accordingly, the respondents revealed which of the services are of a particular interest to the users and which are the preferred channels for accessing the respective service features. Collating these preferences according to the type and focus of the preferred service allowed for the derivation of a user-oriented SC 
public service portfolio on the one hand, and a sketch of multichannel public service provision in SCs on the other hand.

With regard to the first research question, the responses of the participants showed outstanding preferences for smart mobility services, smart public administration and social welfare services. In constrast, smart social services, such as healthcare, education or culture and recreation, as well as environmental services, such as energy monitoring or waste and recycling, are of secondary interest to the user-oriented compilation of SC services. Consequently, the respondents advocate for solving those problems associated with citywide mobility first before turning to the improvement of municipal administration or to the enhancement of existing service structures such as municipal healthcare or the educational system.

Turning towards the second research question, the study reveals that most of the lead users prefer online-based access to public services culminating in a predominant demand for mobile application being accessible via the citizens' smartphones. Indicating a rising public demand for municipal mobile government in the future, the study at hand shows that a SC strategy primarily relying on mobile applications could meet the user's requests for mobile public service solutions. However, as other channels of online access also remain important in the eyes of the respondents, appropriate SC online platforms need to complement the range of smart mobile services in order to meet the users' requirements.

With regard to the target setting of the survey and the associated insights, the lead user survey provided by this study states four contributions. First, reviewing the literature reveals that, to the best of our knowledge, research has not yet constructed a service-delivery model for SC ventures comprising the nature and type of the services provided, not to mention the associated mode of service provision. Against this background, the study provides the reader with a SC service provision framework (cf. Fig. 1) encompassing the responsible administrative units for public (smart) service provision in the city, their range of services provided to the citizens (i.e. the SC service portfolio) as well as the associated channels for accessing the services' features. Second, surveying prospective lead users of urban smart services gives hint about prospective user preferences regarding the type and modalities of SC service provision. By taking into account the lead users' responses, the survey finds a strong public demand for smart mobility services, ICT-augmented municipal public administration and equally distributed social services (cf. Figs. 2 and 3). Third, the survey reveals the new digital generations' preferences for various channels of service interaction (cf. Fig. 4). The results indicate the 'digital shift' in user preferences stating the participants' favor of digital online channels while the relevance of the conventional analog service channels such as service counters, postal mail or public meetings declines. Fourth, the survey confirms the necessity of a citizen-oriented design of SC services as a crucial function-oriented success factor for SC implementation as suggested by previous literature (e.g. Heaton and Parlikad 2019; Gil-Garcia et al. 2015; Hollands 2015; Kitchin 2015). The survey adds provision of an extensive set of full-featured smart urban services, responsiveness and transparency of the services, and maintenance of data security and privacy as additional factors being crucial to SC success. Astonishingly, the respondents deem participatory elements of little importance for SC implementation contradicting the statements of Allen et al. (2020) and Cardullo and Kitchin (2019). 
Scholars might use this study as a guideline for further research endeavours examining both urban conditions and systemic properties that characterize successful SC ventures (i.e. success factors) as well as the composition of SC service provision that enables successful implementation of the SC's agenda. Fig. 1 states a research agenda representing the major topics further research needs to discuss such as SC technology, segments of urban service provision, scope and content of SC services, provision and usage of SC service channels as well as the factors fostering smart service usage. On the contrary, practitioners might use the presented framework as a checklist for SC implementation and as an organizational blueprint representing the major fields for managerial activity arranging the fields of service provision, the composition of the SC service portfolio, the channels for citizen interaction and the design of the SC service interface. The findings derived from the lead user preferences provide valuable practical hints regarding the prioritization of mobility concepts and the expected rise in public demand for mobile applications and web-based service platforms.

Although the results of the survey state interesting insights into the presumed preferences of smart citizens, the study suffers from some limitations weakening the validity of its conclusions. Firstly, the selection of the participants based on the simplifying assumption that the current respondents represent the broad mass of future SC citizens mirroring their current user preferences as the prospective general usage behavior in the future. However, taking post-graduate public administration students as a sample might cause educational and societal biases as these students mostly recruit themselves from the academic and wealthy class of society neglecting non-academic, less affluent parts of the population. Accordingly, this lead-user survey states as a preliminary study providing a first notion of user preferences for SC services but facing restrictions in empirical validity. Further empirical and exploratory research should thus verify the above-mentioned statements by extending the body of conceivable lead users to achieve a representative sample and to avoid sample selection biases.

Secondly, the results concerning the success factors only provide insights into the relevance of the success factors but do not allow for any conclusions about the causal effects on usage intensity. However, for the time being, conducting empirical research concerning the causal effects of SC service success factors on their usage intensity appears to be difficult as practical implementation of SCs is still in its infancy. In order to examine cause-and-effect relationships of SC success factors, further empirical investigation requires the examination of user behavior in established SCs such Singapore, San Francisco or Vienna (Wirtz et al. 2019a) offering a broad and balanced range of public smart services without neglecting large parts of the SC service portfolio presented in Fig. 1.

Thirdly, preferences for municipal services are a local and temporary phenomenon representing the public requirements and needs that stem from geographic, demographic, cultural and socio-economic conditions prevailing in the respective cities. Consequently, a generalization of the results of the presented survey deserve caution as this study refers to German lead users. For other countries showing substantial differences in geographical, demographic, cultural or socio-economic characteristics, other preferences may apply. Although the authors are confident that the sample at hand represents a sound representation of lead users in western developed countries, further research should replicate the examination of lead users' preferences in order to verify the results and to estimate and compare citizen preferences within and across the world. Countries 
that are already home to leading SC projects (e.g. USA, Austria, Singapore, South Korea, etc.) can serve as reference points for prospective SC user and lead user surveys (cf. Wirtz et al. 2019a).

Overall, although SC literature emphasizes the necessity to design SCs in a useroriented manner aligning its range of public smart services to urban demand, research has not examined the preferences of SC user to a sufficient extent. By taking the first step towards a notion of public demand for smart municipal services, the current study attains first insights by assessing the estimates and the intended usage behavior of prospective SC lead users. Although there remain several open issues further research needs to solve, the results suggest that smart mobility states the most important field of action whereas service development in SCs needs to focus the embedment into mobile applications and online service platforms.

Funding Open Access funding enabled and organized by Projekt DEAL. This research study as a part of the research project "Wissens- und Ideentransfer für Innovation in der Verwaltung" (WITI) was funded by the Research Initiative "Innovative Hochschule" of the German Federal Ministry of Education and Research (Grant No.: 03IHS041A).

\section{Compliance with Ethical Standards}

Conflict of Interest The authors declare that there exists no conflict of interest.

Informed Consent None (not applicable).

Ethical Approval None (not applicable).

Declaration of Submission Uniqueness We confirm that this manuscript has not been published elsewhere and is not under consideration by another journal. All authors approved the manuscript and agreed with its submission to "Public Organization Review".

Open Access This article is licensed under a Creative Commons Attribution 4.0 International License, which permits use, sharing, adaptation, distribution and reproduction in any medium or format, as long as you give appropriate credit to the original author(s) and the source, provide a link to the Creative Commons licence, and indicate if changes were made. The images or other third party material in this article are included in the article's Creative Commons licence, unless indicated otherwise in a credit line to the material. If material is not included in the article's Creative Commons licence and your intended use is not permitted by statutory regulation or exceeds the permitted use, you will need to obtain permission directly from the copyright holder. To view a copy of this licence, visit http://creativecommons.org/licenses/by/4.0/.

\section{References}

Abella, A., Ortiz-de-Urbina-Criado, M., \& De-Pablos-Heredero, C. (2019). A methodology to design and redesign services in smart cities based on the citizen experience. Information Polity, 24(2), 183-197.

Allen, B., Tamindael, L. E., Bickerton, S. H., \& Cho, W. (2020). Does citizen coproduction lead to better urban services in smart cities projects? An empirical study on e-participation in a mobile big data platform. Government Information Quarterly, 37(1), 101412.

Allwinkle, S., \& Cruickshank, P. (2011). Creating smart-er cities: An overview. Journal of Urban Technology, 18(2), 1-16.

Angelidou, M. (2015). Smart cities: A conjuncture of four forces. Cities, 47, 95-106. 
Anttiroiko, A.-V., Valkama, P., \& Bailey, S. J. (2014). Smart cities in the new service economy: Building platforms for smart services. AI \& SOCIETY, 29(3), 323-334.

Biagi, B., Ladu, M. G., \& Meleddu, M. (2018). Urban quality of life and capabilities: An experimental study. Ecological Economics, 150, 137-152.

Cardullo, P., \& Kitchin, R. (2019). Being a 'citizen' in the smart city: Up and down the scaffold of smart citizen participation in Dublin, Ireland. GeoJournal, 84(1), 1-13.

Chourabi, H., Nam, T., Walker, S., Gil-Garcia, J. R., Mellouli, S., Nahon, K., et al. (2012). Understanding smart cities: An integrative framework. In Z. Lee, C. Cheung, \& D. Thadani (Eds.), 45th Hawaii International Conference on System Sciences (HICSS), Maui, HI, USA, 04.01.- 07.01.2012 (pp. 22892297). IEEE.

Dreyer, S., Olivotti, D., Lebek, B., \& Breitner, M. H. (2019). Focusing the customer through smart services: A literature review. Electronic Markets, 29(1), 55-78.

El-Haddadeh, R., Weerakkody, V., Osmani, M., Thakker, D., \& Kapoor, K. K. (2019). Examining citizens' perceived value of internet of things technologies in facilitating public sector services engagement. Government Information Quarterly, 36(2), 310-320.

Gil-Garcia, J. R., Pardo, T. A., \& Nam, T. (2015). What makes a city smart? Identifying core components and proposing an integrative and comprehensive conceptualization. Information Polity, 20(1), 61-87.

Heaton, J., \& Parlikad, A. K. (2019). A conceptual framework for the alignment of infrastructure assets to citizen requirements within a smart cities framework. Cities, 90, 32-41.

Hollands, R. G. (2008). Will the real smart city please stand up? City, 12(3), 303-320.

Hollands, R. G. (2015). Critical interventions into the corporate smart city. Cambridge Journal of Regions, Economy and Society, 8(1), 61-77.

Johnson, P. A., Robinson, P. J., \& Philpot, S. (2020). Type, tweet, tap, and pass: How smart city technology is creating a transactional citizen. Government Information Quarterly, 37(1), 101414.

Joss, S., Cook, M., \& Dayot, Y. (2017). Smart cities: Towards a new citizenship regime? A discourse analysis of the British Smart City standard. Journal of Urban Technology, 24(4), 29-49.

Kitchin, R. (2015). Making sense of smart cities: Addressing present shortcomings. Cambridge Journal of Regions, Economy and Society, 8(1), 131-136.

Lamberti, L., Benedetti, M., \& Chen, S. (2014). Benefits sought by citizens and channel attitudes for multichannel payment services: Evidence from Italy. Government Information Quarterly, 31(4), 596609.

Lüthje, C., \& Herstatt, C. (2004). The Lead user method: An outline of empirical findings and issues for future research. R\&D Management, 34(5), 553-568.

Macke, J., Rubim Sarate, J. A., \& de Atayde Moschen, S. (2019). Smart sustainable cities evaluation and sense of community. Journal of Cleaner Production, 239(118103), 118103.

Marrone, M., \& Hammerle, M. (2018). Smart cities: A review and analysis of stakeholders' literature. Business \& Information Systems Engineering, 60(3), 197-213.

Mora, L., Bolici, R., \& Deakin, M. (2017). The first two decades of Smart-City research: A Bibliometric analysis. Journal of Urban Technology, 24(1), 3-27.

Mossberger, K., Wu, Y., \& Crawford, J. (2013). Connecting citizens and local governments? Social media and interactivity in major U.S. cities. Government Information Quarterly, 30(4), 351-358.

Nam, T., \& Pardo, T. A. (2011). Conceptualizing smart city with dimensions of technology, people, and institutions. In J. Bertot, K. Nahon, S. A. Chun, L. Luna-Reyes, \& V. Atluri (Eds.), The 12th Annual International Digital Government Research Conference, College Park, Maryland, 12.06. - 15.06.2011 (p. 282). New York: ACM press.

Neirotti, P., de Marco, A., Cagliano, A. C., Mangano, G., \& Scorrano, F. (2014). Current trends in Smart City initiatives: Some stylised facts. Cities, 38, 25-36.

Pereira, G. V., Parycek, P., Falco, E., \& Kleinhans, R. (2018). Smart governance in the context of smart cities: A literature review. Information Polity, 23(2), 143-162.

United Nations. (2014). United Nations E-government survey 2014: E-government for the future we want. New York, New York, USA.

Vanolo, A. (2016). Is there anybody out there? The place and role of citizens in tomorrow's smart cities. Futures, 82, 26-36.

Visnjic, I., Neely, A., Cennamo, C., \& Visnjic, N. (2016). Governing the city: Unleashing value from the business ecosystem. California Management Review, 59(1), 109-140.

Von Hippel, E. (1986). Lead users: A source of novel product concepts. Management Science, 32(7), 791805.

Webster, C. W. R., \& Leleux, C. (2018). Smart governance: Opportunities for technologically-mediated citizen co-production. Information Polity, 23(1), 95-110. 
Wirtz, B. W., \& Langer, P. F. (2017). Public multichannel management - An integrated framework of off- and online multichannel government services. Public Organization Review, 17(4), 563-580.

Wirtz, B. W., Müller, W. M., \& Schmidt, F. (2019a). Public smart service provision in smart cities: A casestudy-based approach. International Journal of Public Administration, 2(1), 1-18.

Wirtz, B. W., Weyerer, J. C., \& Schichtel, F. T. (2019b). An integrative public IoT framework for smart government. Government Information Quarterly, 36(2), 333-345.

Woetzel, J., Remes, J., Boland, B., Lv, K., Sinha, S., Strube, G., et al. (2018). Smart cities: Digital solutions for a more livable future: Executive summary

Publisher's Note Springer Nature remains neutral with regard to jurisdictional claims in published maps and institutional affiliations.

Bernd W. Wirtz Chair holder chair for Information and Communication Management, German University of Administrative Science Speyer.

Wilhelm M. Müller Research associate chair for Information and Communication Management, German University of Administrative Science Speyer

Florian W. Schmidt Research associate chair for Information and Communication Management, German University of Administrative Science Speyer. 